\title{
Peramalan Tinggi dan Periode Gelombang Signifikan Di Perairan Dangkal (Studi Kasus Perairan Semarang)
}

\author{
Alfi Satriadi \\ Departemen Oseanografi, Fakultas Perikanan dan Ilmu Kelautan, Universitas Diponegoro \\ Kampus Tembalang, Semarang 50275 Telp/Fax. 024-7474698 \\ Email: satriadi@undip.ac.id
}

\begin{abstract}
Abstrak
Gelombang menjalar dari perairan dalam menuju perairan dangkal. Penjalaran gelombang merupakan bentuk dari adanya gangguan pada suatu medium, dalam hal ini medium air. Salah satu bentuk dari gangguan tersebut adalah gaya gesek angin. Sehingga arah dan kecepatan angin dapat digunakan untuk menentukan tinggi dan periode gelombang yang dihasilkan. Metode Sverdrup, Munk, dan Bretschneider (SMB) digunakan dalam penelitian ini untuk menentukan tinggi dan periode gelombang signifikan di perairan dangkal khususnya perairan Semarang. Data angin yang digunakan untuk meramalkan tinggi dan periode gelombang diperoleh dari European Centre for Medium-Range Weather Forecasts (ECMWF) selama 10 tahun (2007-2016). Koreksi durasi dilakukan untuk mendapatan data angin rata-rata setiap jam. Selanjutnya melakukan koreksi stabilitas dan menentukan nilai wind stress factor dimana nilai ini, fetch efektif, dan kedalaman perairan digunakan untuk mendapatkan nilai tinggi dan periode gelombang signifikan. Hasil penelitian menunjukan arah angin dominan pada musim Timur, musim Peralihan II, dan musim Barat menuju ke arah Tenggara. Sedangkan arah angin dominan pada musim Peralihan I menuju ke arah Selatan. Musim Barat memiliki variasi kecepatan angin lebih tinggi dari ketiga musim lainnya. Demikian pula, tinggi dan periode gelombang signifikan pada musim Barat adalah tertinggi dengan nilai 1,227 meter dan 5,175 detik. Sebaliknya, pada musim Peralihan II memiliki tinggi dan periode gelombang signifikan terendah dengan nilai 0,577 meter dan 3,391 detik. Tinggi dan periode gelombang signifikan di perairan Semarang sangat dipengaruhi oleh angin muson.
\end{abstract}

Kata Kunci: Tinggi dan Periode Gelombang Signifikan, Metode SMB, Perairan Semarang

\begin{abstract}
Ocean waves propagation from depth water into shallow water has been becoming important aspect to determine waves characteristic. In particular, waves is manifestation of energy, such as wind stress in this case, that is transferred into a medium. Moreover, wind speed and direction can be used to predict significant wave height and period.Sverdrup, Munk, and Bretschneider (SMB) method are employed to predict significant wave height and period at Semarang waters. This method is based on wind data, speed and direction, to forecast where the data used in this research were collected from European Centre for Medium-Range Weather Forecasts (ECMWF) from 2007 to 2016. Data Corrections were applied in this research including duration and stability correction. As a result, from this correction, wind stress factor was established to compute significant wave height and period. The result showed that in East season, First Transitional season, and West season, wind direction was dominated from the Southeast. Differently, wind blew to the South dominated in Second Transitional season. West season had significantly high wind speed variation compared to other seasons. In addition, It had 1,227 meter of significant wave height and 5,175 second of significant wave period. On the contrary, Second Transitional season had lowest significant wave height and periods, 0,577 meter and 3,391 second respectively.
\end{abstract}

Keywords: Significant Wave Height and Period, SMB Method, Semarang Waters

\section{PENDAHULUAN}

Fenomena gelombang yang ada di laut merupakan hasil perwujudan energi yang diakibatkan karena adanya gangguan yang merambat dari perairan dalam menuju ke perairan dangkal (Liu dkk. 2015). Gangguan-gangguan

\footnotetext{
*Corresponding author

http://ejournal.undip.ac.id/index.php/buloma

Diterima/Received : 12-01-2017

buloma.undip@gmail.com

Disetujui/Accepted : 05-02-2017
} 
tersebut dapat berasal dari angin, gaya tarik benda astronomi (bulan dan matahari), pergerakan lempeng dan lain sebagainya. Koutitas (1988) mengklasifikasikan gelombang berdasarkan periodenya. Tipe gelombang berdasarkan periodenya yang digunakan dalam penelitian ini adalah gelombang yang dibangkitkan oleh angin, dengan periode antara 0 sampai 10 detik.

Sulitnya pengambilan data gelombang secara insitu di laut menjadi suatu masalah tersendiri. Solusi dari masalah tersebut adalah menggunakan data angin untuk mengetahui tinggi dan periode gelombang signifikan. Konsep tinggi gelombang signifikan telah lama dikemukakan oleh Munk (1944), dimana konsep ini dapat merepresentasikan tinggi gelombang sebenarnya di lapangan. Data angin yang digunakan dalam peramalan gelombang dapat diperoleh dari hasil pengukuran di stasiun angin atau berasal dari data pemodelan yang telah dianalisis.

Peramalan gelombang pada penelitian ini dilakukan menggunakan metode SMB, Sverdrup dan Munk (1947) dan Bretschneider (1951), untuk gelombang pada perairan dangkal dan diaplikasikan pada perairan semarang. Tujuan dalam studi ini adalah untuk memberikan informasi mengenai peramalan gelombang di perairan dangkal khususnya di perairan Semarang (Gambar 1).

\section{MATERI DAN METODE}

Penelitian ini dilakukan dalam empat tahap. Tahap pertama adalah pengumpulan data dimana data yang digunakan adalah data arah dan kecepatan angin dan data kedalaman perairan di stasiun angin. Data arah dan kecepatan angin didapatkan dari European Centre for MediumRange Weather Forecasts (ECMWF) yang merupakan data kecepatan dan arah angin reanalysis rata-rata dalam satu hari dengan ketinggian 10 meter dari tahun 2007-2016. Stasiun data angin terletak pada koordinat $110,375^{\circ} \mathrm{E}$ dan $6,875^{\circ} \mathrm{S}$ dengan kedalaman 14 meter. Data kedalaman di perairan stasiun angin diperoleh dari National Oceanic and Atmospheric Administration (NOAA).

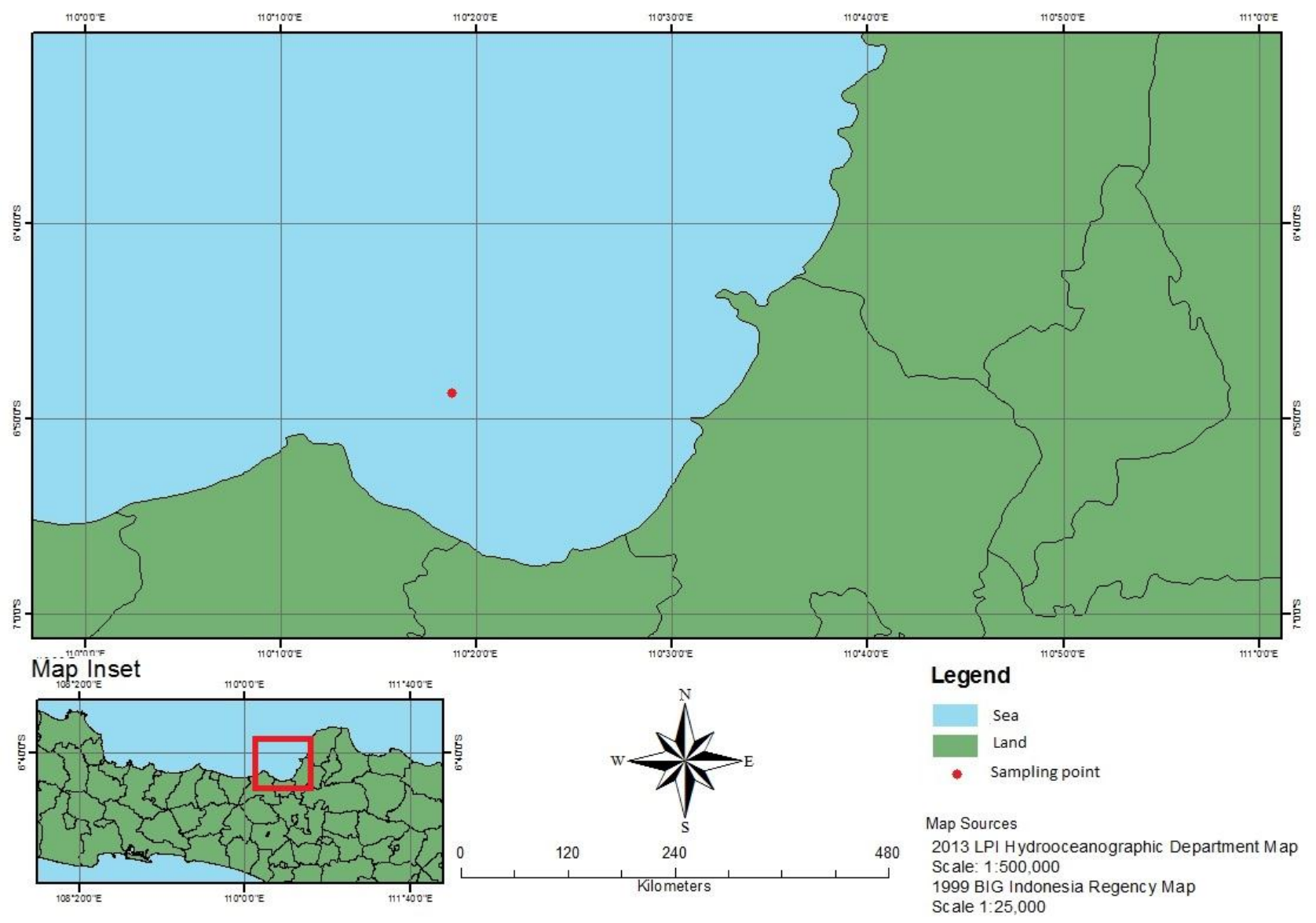

Gambar 1. Peta area penelitian dan titik pengambilan data. 
Tahap kedua adalah pengolahan data angin untuk mengetahui arah angin dominan pada setiap musim yaitu musim Barat, musim Peralihan I, musim Timur dan musim Peralihan II. Angin musim Barat terjadi pada bulan Desember hingga Februari, angin musim Peralihan I terjadi pada bulan Maret hingga Mei, angin musim Timur terjadi pada bulan Juni hingga Agustus dan angin pada musim Peralihan II terjadi pada bulan September hingga November. Data angin ini diolah dengan menggunakan perangkat lunak WRPLOT untuk memvisualisasikan data arah dan kecepatan angin dalam bentuk mawar angin (windrose). Dari windrose dapat dilihat arah angin dominan setiap musim yang selanjutnya untuk menentukan nilai panjang fetch. Perhitungan fetch efektif dilakukan dengan mengaplikasikan metode Sverdrup, Munk dan Bretschneider (SMB) dimana arah angin dominan menjadi garis fetch poros untuk menentukan garis fetch kurang lebih $45^{0}$ ke kanan dan ke kiri dengan interval $6^{0}$. Kemudian panjang fetch efektif masing-masing musim didapat dengan menggunakan persamaan (1). Dari persamaan tersebut $X_{i}$ adalah data panjang fetch ke-i dan $\alpha_{\mathrm{i}}$ adalah besarnya sudut ke-I (Etemad-Shahidi dkk. 2009).

$$
X=\frac{\sum_{i=1}^{15} X_{i} \cos \alpha_{i}}{\sum_{i=1}^{15} \cos \alpha_{i}}
$$

Tahap ketiga dilakukan perhitungan pada data angin untuk mendapatkan wind stress factor (Ua). Terdapat empat jenis koreksi data angin pada tahap ini, diantarannya koreksi ketinggian, koreksi durasi, koreksi stabilitas, dan koreksi efek lokasi (U.S. Army, 2008). Koreksi ketinggian tidak dilakukan pada penelitian ini karena data angin yang diperoleh sudah berada pada ketinggian 10 meter. Demikian juga dengan koreksi efek lokasi yang tidak dilakukan karena data angin yang diperoleh bukan merupakan data angin hasil pengukuran di darat. Koreksi durasi dilakukan untuk mendapatkan nilai kecepatan angin rata-rata selama durasi angin yang ditentukan. Di dalam penelitian ini kecepatan angin rata-rata setiap satu jam didapatkan melalui persamaan (2), (3), (4a), (4b) dan (5) (U.S. Army, 1984).

$$
t=\frac{1069}{U_{f}}
$$

$$
\begin{gathered}
U_{f}=U_{t} \\
\frac{U_{t}}{U_{3600}}=1,277+0,296 \tanh \left(0,9 \log \frac{45}{t}\right) \\
\text { untuk } 1<t<3600 \text { detik } \\
(4 \mathrm{a}) \\
\frac{U_{t}}{U_{3600}}=-0,15 \log t+1,5334 \\
\text { untuk } 3600<t<36000 \text { detik } \\
U_{3600}=\frac{(4 \mathrm{~b})}{\left(\frac{U_{t}}{U_{3600}}\right)}
\end{gathered}
$$

Dalam hal ini $\mathrm{t}$ adalah lamanya durasi angin bertiup dalam satuan detik, $\mathrm{U}_{\mathrm{f}}$ adalah kecepatan angin maksimum dan $U_{t}$ adalah kecepatan angin selama durasi t dengan satuan meter per detik. Koreksi stabilitas bertujuan untuk menambahkan pengaruh perbedaan temperatur di udara dan di laut dimana dalam penelitian ini tidak dilakukan perngukuran temperatur di udara maupun di laut sehingga pada persamaan (6) nilai Rt diasumsikan sama dengan 1,1. Kemudian perhitungan dilanjutkan dengan persamaan (7) untuk mendapatkan nilai wind stress factor. Parameter yang digunakan dalam persamaan ini adalah $\mathrm{U}$ yang merupakan kecepatan angin yang telah dilakukan koreksi stabilitas dan $\mathrm{U}_{\mathrm{a}}$ adalah wind stress factor.

$$
\begin{gathered}
U=R_{T} U_{3600} \\
U_{a}=0,71 U^{1,23}
\end{gathered}
$$

Tahap keempat adalah perhitungan nilai tinggi dan periode gelombang signifikan $\left(\mathrm{H}_{\mathrm{s}}\right.$ dan $\mathrm{T}_{\mathrm{s}}$ ) di perairan dangkal. Perhitungan tinggi dan periode gelombang signifikan dilakukan dengan menggunakan persamaan (8) dan (9) (U.S. Army, 1984; Karimpour dkk. 2017).

\section{HASIL DAN PEMBAHASAN}

Gambar 2 menunjukan distribusi angin ratarata setiap 6 jam di perairan Semarang pada musim Barat, musim Peralihan I, musim Timur dan musim Peralihan II dari tahun 2007 hingga 2016. Untuk mempermudah dalam menganalisis data angin, mawar angin yang digunakan dalam penelitian ini hanya menampilkan delapan arah mata angin dan menginterpretasikan. Berdasarkan data penelitian, terdapat lima arah angin dominan untuk masing-masing musim. Pada musim Barat (Gambar 2a), arah angin dominan adalah menuju 


$$
\begin{gathered}
H_{S}=0,283 \frac{U_{a}^{2}}{g} \tanh \left[0,53\left(\frac{g h}{U_{a}^{2}}\right)^{3 / 4}\right] \tanh \left[\frac{0,00565\left(\frac{g X}{U_{a}^{2}}\right)^{1 / 2}}{\tanh \left[0,53\left(\frac{g h}{U_{a}^{2}}\right)^{3 / 4}\right]}\right] \\
T_{S}=7,54 \frac{U_{a}}{g} \tanh \left[0,833\left(\frac{g h}{U_{a}^{2}}\right)^{3 / 8}\right] \tanh \left\{\frac{0,0379\left(\frac{g X}{U_{a}^{2}}\right)^{1 / 3}}{\tanh \left[0,833\left(\frac{g h}{U_{a}^{2}}\right)^{3 / 8}\right]}\right\}
\end{gathered}
$$

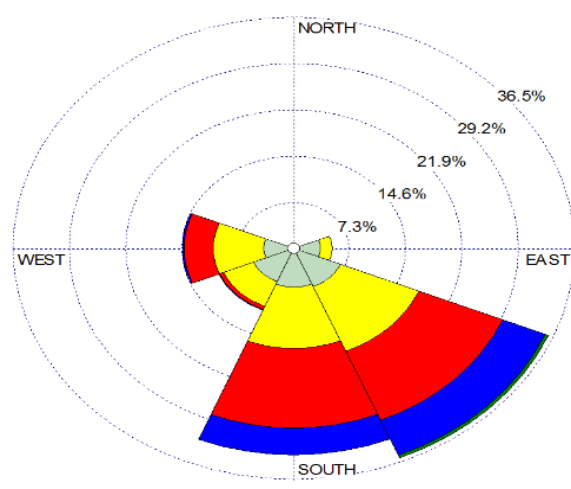

(a)

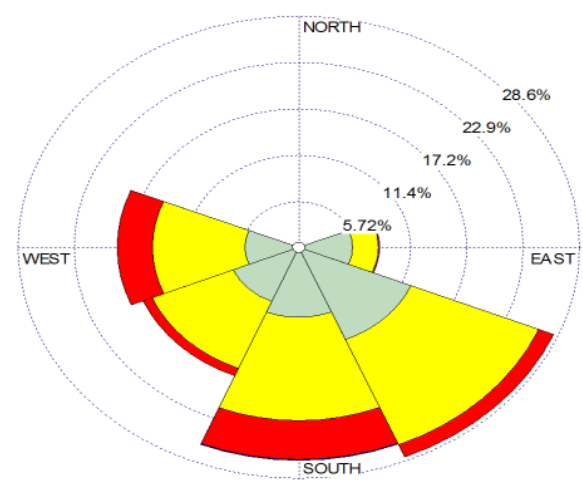

(c)

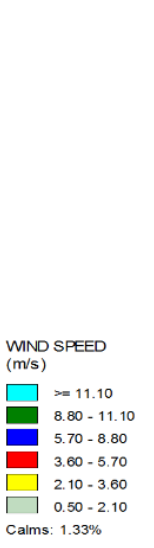

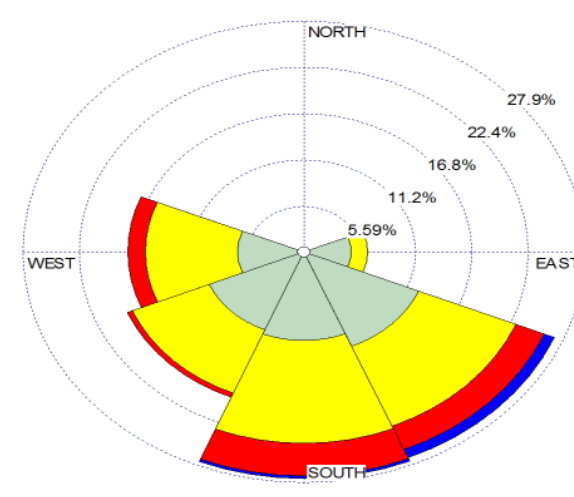

(b)

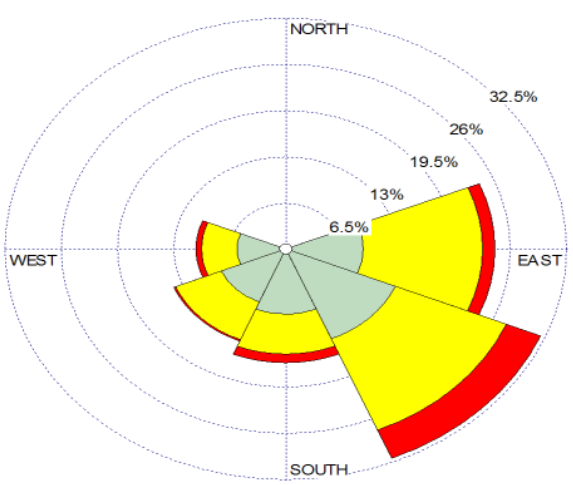

(d)

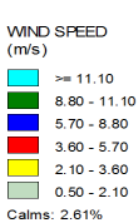

WND SPEED $(\mathrm{m} / \mathrm{s})$ $=-11.10$
$8.80-11.10$
$570-0.80$ $8.80-11.10$
$5.70-8.80$ $3.60-5.70$ $2.10-3.60$
$0.50-2.10$ Calms: $3.19 \%$

Gambar 2. Windrose Setiap Musim Perairan Semarang. (a) Musim Barat, (b) Musim Peralihan I, (c) Musim Timur, dan (d) Musim Peralihan II

ke arah $35,77 \%$ dan 32,55\%. Kurniawan dkk. (2011) mengemukakan bahwa arah angin di Laut Jawa pada bulan Desember, Januari, dan Februari cenderung kearah Timur kemudian berbelok kearah Selatan. Demikian halnya dengan musim Timur dan Peralihan II (Gambar 2c dan 2d), arah angin dominan menuju ke arah Tenggara akan tetapi dengan frekuensi yang berbeda, 28,04\% untuk musim Timur dan $31,86 \%$ untuk musim Peralihan II. Sedangkan arah angin dominan pada musim Peralihan I menunjukan arah Selatan dengan frekuensi kejadian sebesar 27,39\%. Perbandingan distribusi frekuensi setiap musim ditunjukan oleh Gambar 
Buletin Oseanografi Marina April 2017 Vol 6 No 1:17-23

Tabel 1. Perbandingan Kecepatan Angin Rata-rata Setiap Jam Antar Musim

\begin{tabular}{|c|c|c|c|c|c|c|}
\hline \multirow{2}{*}{ Musim } & \multicolumn{4}{|c|}{ Koreksi Durasi } & \multirow{2}{*}{ Rasio Rata-rata } & \multirow{2}{*}{$\begin{array}{l}\text { Standar } \\
\text { Deviasi }\end{array}$} \\
\hline & $\mathrm{U}(\max )$ & $\mathrm{U}(3600)$ & $\mathrm{U}(7200)$ & $\mathrm{U}(10800)$ & & \\
\hline Barat & 9,304 & 6,917 & 6,604 & 6,422 & 0,314 & 0,0013 \\
\hline Peralihan I & 8,515 & 6,357 & 6,070 & 5,902 & 0,288 & 0,0006 \\
\hline Timur & 5,926 & 4,487 & 4,284 & 4,165 & 0,203 & 0,0009 \\
\hline Peralihan II & 5,630 & 4,269 & 4,076 & 3,964 & 0,193 & 0,001 \\
\hline Rata-rata & 29,375 & 22,03 & 21,034 & 20,453 & & \\
\hline
\end{tabular}

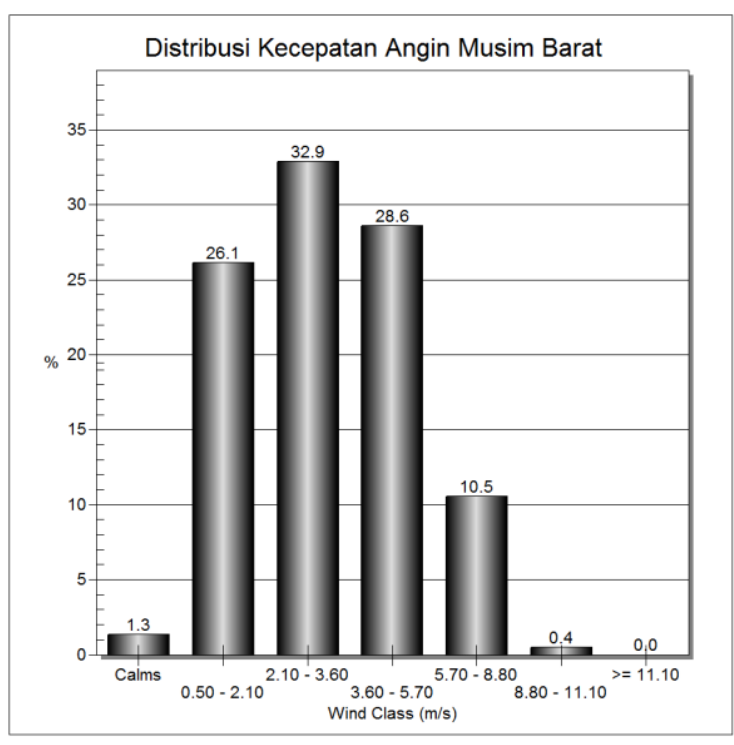

(a)

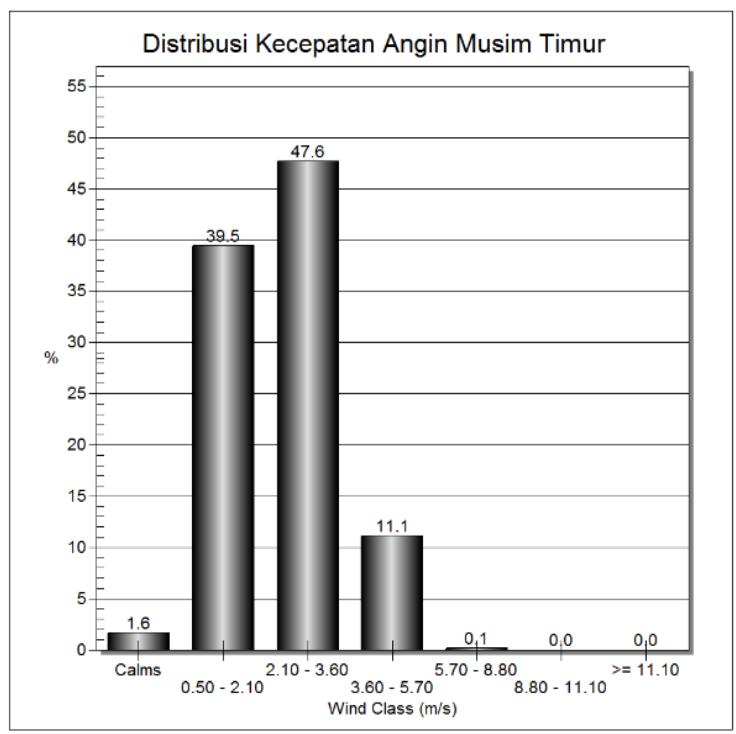

(c)

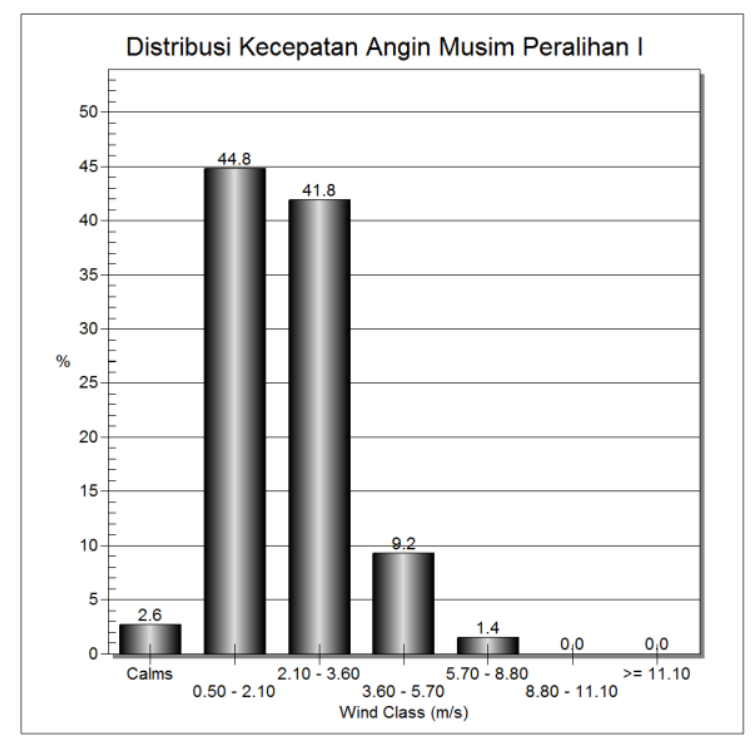

(b)

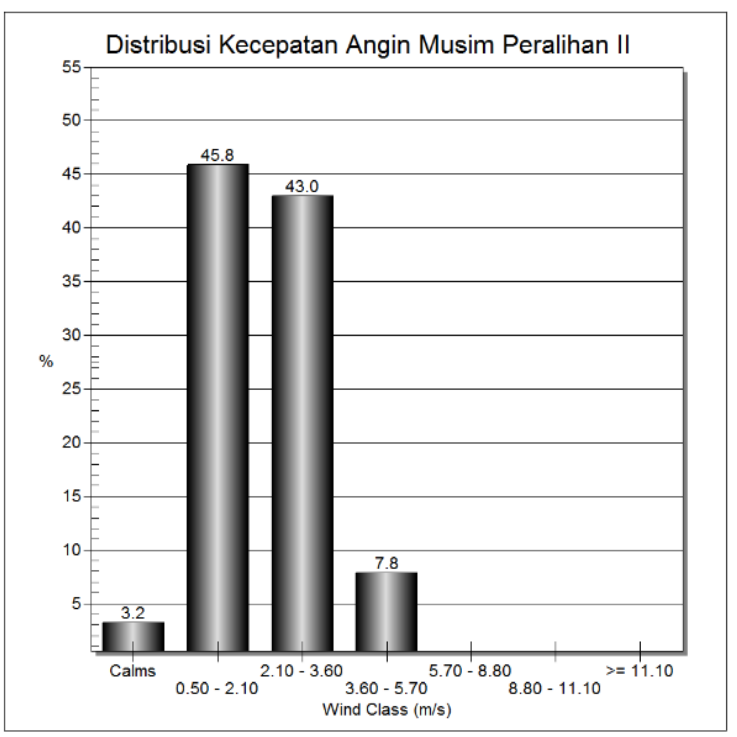

(d)

Gambar 3. Distribusi Kejadian Kecepatan Angin Perairan Semarang Setiap Musim. (a) Musim Barat, (b) Musim Peralihan I, (c) Musim Timur, dan (d) Musim Peralihan II 
Gambar 3 menunjukan dengan jelas bahwa kecepatan angin pada musim Peralihan I, musim Timur dan Peralihan II dominan pada kecepatan $0,5-3,6 \mathrm{~m} / \mathrm{s}$. Musim Barat, kecepatan angin dominan pada rentang antara 0,5 dan $5,7 \mathrm{~m} / \mathrm{s}$.

Distribusi kejadian kecepatan angin ditunjukan pada Gambar 3. Kecepatan angin cenderung bervariasi pada musim Barat dan hanya pada musim ini terdapat kecepatan angin tertinggi $(8,8-11,1 \mathrm{~m} / \mathrm{s})$ dengan frekuensi sebesar $0,4 \%$. Sedangkan frekuensi kecepatan angin dominan adalah 2,1-3,6 m/s dengan frekuensi sebesar 32,9\%. Distribusi kecepatan angin pada musim Peralihan I dan Peralihan II menunjukan frekuensi kecepatan angin tertinggi pada 0,5-2,1 m/s dan frekuensi kecepatan angin tertinggi berikutnya pada 2,1-3,6 m/s. Hasil yang berbeda ditunjukan pada distribusi kecepatan angin pada musim Timur yaitu frekuensi kecepatan angin tertinggi pada kecepatan 2,1-3,6 m/s, kemudian kecepatan angin tertinggi berikutnya pada kecepatan 0,5-2,1 $\mathrm{m} / \mathrm{s}$. Tabel 1 menunjukan hasil dari koreksi durasi. Koreksi ini dilakukan untuk mendapatkan kecepatan angin rata-rata setiap jam.

Dalam penelitian ini, untuk mengetahui bahwa data rata-rata kecepatan angin setiap jam dapat digunakan untuk peramalan adalah dengan membandingkan data kecepatan angin rata-rata setiap satu jam dengan kecepatan angin rata-rata setiap dua jam dan tiga jam. Berdasarkan tabel 1, kecepatan angin rata-rata satu jam dapat digunakan karena memiliki nilai kurang dari 3 m/s. U.S. Army (1984) mengatakan bahwa perbandingan kecepatan angin setiap jam lebih dari $3 \mathrm{~m} / \mathrm{s}$ sampai $5 \mathrm{~m} / \mathrm{s}$ menunjukan akurasi peramalan gelombang tidak akurat. Dari tabel tersebut menunjukan bahwa musim Barat memiliki kecepatan angin maksimum tertinggi dari ketiga musim lainnya. Sedangkan musim Peralihan II memiliki kecepatan angin terendah. Hasil perhitungan standar deviasi dari rasio ratarata kecepatan angin setiap jam menjukan nilai simpangan yang sangat kecil. Hal ini berarti bahwa data kecepatan angin setiap jam tidak menunjukan variasi yang tidak terlalu signifikan sehingga data angin setiap jam dari masingmasing musim dapat digunakan.

Berdasarkan hasil pengolahan data diperoleh tinggi dan periode gelombang signifikan pada setiap musim (Tabel 2). Musim Barat memiliki nilai tinggi dan periode gelombang signifikan tertinggi dibandingkan dengan musim Peralihan I, musim Timur, dan musim Peralihan II. Jika data tersebut dihubungkan dengan distribusi kecepatan angin dengan asumsi durasi dan fetch angin yang konstan, nilai tinggi gelombang memiliki hubungan yang linier dengan kecepatan angin (Smith dan Waseda, 2008). Hal ini berlaku pada musim Barat dimana memiliki distribusi frekuensi kecepatan angin tinggi (lebih dari $3,6 \mathrm{~m} / \mathrm{s}$ ) dibandingkan tiga musim lainnya yang menghasilkan tinggi gelombang signifikan tertinggi.

Berdasarkan data penelitian, pada musim Peralihan I, musim Timur, dan musim Peralihan II memiliki pola distribusi kecepatan angin yang hampir seragam, namun frekuensi distribusi kecepatan angin dominan pada $0,5-3,6 \mathrm{~m} / \mathrm{s}$. Tabel 2 menunjukan bahwa musim Barat memiliki nilai tinggi dan periode gelombang signifikan tertinggi yaitu 1,227 meter dan 5,175 detik. Sedangkan nilai tinggi dan periode gelombang signifikan pada musim Peralihan II sebesar 0,577 meter dan 3,391 detik. Menurut Hadi dan Sugianto (2012), tinggi gelombang maksimum di perairan semarang mencapai 2 meter dengan periode 6,8 detik, sedangkan pada musim Peralihan tinggi gelombang maksimum mencapai 1.99 meter dan periode 6.8 detik. Akan tetapi pada musim Timur menunjukan tinggi gelombang maksimum lebih rendah daripada musim Peralihan yaitu mencapai 1,49 meter dengan periode 6,1 detik. Jika dibandingkan, terdapat dua hal yang berbeda, Disatu sisi menunjukan bahwa tinggi gelombang di perairan Semarang pada musim Barat memiliki tinggi gelombang lebih tinggi daripada ketiga musim lainnya. Disisi lain menunjukan kontradiksi antara perbandingan tinggi gelombang, signifikan dan maksimum, yang tidak ekuivalen.

Tabel 2. Tinggi dan Periode Gelombang Signifikan Hasil Peramalan.

\begin{tabular}{ccc}
\hline Musim & Hs & Ts \\
\hline Barat & 1,227 & 5,175 \\
Peralihan I & 1,098 & 4,849 \\
Timur & 0,634 & 3,562 \\
Peralihan II & 0,577 & 3,391 \\
\hline
\end{tabular}

Pada bulan Desember hingga Februari (musim Barat), Aprilleria dkk. (2015) menyatakan bahwa angin berhembus dari Utara Asia dengan arah Timur laut kemudian setelah melewati garis katulistiwa arah angin dibelokan ke arah Timur. Sedangkan pada bulan Juni hingga Agustus (musim Timur) angin behembus dari Australia menuju ke Indonesia dari arah Tenggara kemudian setelah melewati garis katulistiwa arah angin dibelokan ke arah Timur laut. Hal ini 
menunjukan bahwa pada musim Barat angin memiliki pengaruh yang kuat dalam pembangkitan gelombang di perairan Semarang. Sedangkan pada musim Timur arah angin dari Tenggara yang terhalang pulau sehingga tinggi gelombang signifikan pada musim ini tidak sebesar musim Barat. Tinggi dan periode gelombang signifikan pada musim Peralihan I masih dipengaruhi oleh musim Barat, demikian halnya dengan musim Peralihan II yang masih dipengaruhi oleh musim Timur.

\section{KESIMPULAN}

Distribusi kecepatan angin pada musim Barat selama tahun 2007 hingga 2016 lebih bervariasi dari ketiga musim lainnya. Tinggi dan periode gelombang signifikan tertinggi di perairan Semarang adalah pada musim Barat. Hal tersebut berkaitan dengan angin muson Barat yang berhembus dari utara asia yang kemudian dibelokan ke arah Timur setelah melewati garis katulistiwa. Sebaliknya musim Peralihan II menunjukan nilai tinggi dan periode gelombang signifikan terendah karena berada pada transisi waktu angin muson Timur menjadi angin muson Barat.

\section{DAFTAR PUSTAKA}

Aprilleria, V., M. Maharani, dan K. I. Solihah. 2015. Influence of Monsoon in Indonesia as a Renewable Energy Source and Sustainable Development. Proceeding of $23^{\text {rd }}$ TheIIER Conference. Singapore, 25 April 2015. p: 2022.

Bretschneider, C. L. 1957. Revisions in Wave Forecasting: Deep and Shallow Water. Proceeding of the $6^{\text {th }}$ Conference on Coastal Engineering, Council on Wave Research. p: $1-18$.

Ethemad-Shahidi, A., M. H. Kazeminezhad, dan S. J. Mousavi. 2009. On the Prediction of
Wave Parameters Using Simplified Methods. Journal of Coastal Reseach. SI 56:505-509.

Hadi, S. dan D. N. Sugianto. 2012. Model Distribusi Kecepatan Angin untuk Peramalan Gelombang dengan Menggunakan Metode Darbyshire dan SMB di Perairan Semarang. Buletin Oseanografi Marina. 1:25-32.

Karimpour, A., Q. Chen, dan R. R. Twilley. 2017. Wind Wave Behavior in Fetch and Depth Limited Estuaries. Scientific Reports. 7:40654.

Koutitas, C. G. 1988. Mathematical Models in Coastal Engineering. Pentech Press Ltd. 156 hlm.

Kurniawan, R., M. N. Habibie, dan Suratno. 2011. Variasi Bulanan Gelombang Laut di Indonesia. Jurnal Meteorologi dan Geofisika. 12(3):221-232.

Liu, K., Q. Chen, dan J. M. Kalhatu. 2015. Modeling Wind Effects on Shallow Water Waves. Journal of Waterway, Port, Coastal, and Ocean Engineering. 142(1):1-8.

Munk, W. H. 1944. Proposed Uniform Procedure for Observing Waves and Interpreting Instrument Records. Scripps Institute of Oceanography. California.

Smith, T. L. dan T. Waseda. 2008. Wind Wave Growth at Short Fetch. Journal of Physical Oceanography. 38:1597-1606.

Sverdrup, H. U. dan Munk, W. H. 1947. Wind, Sea, and Swell: Theory of Relations for Forecasting. U.S. Navy Department, Hydrographic Office. $44 \mathrm{hlm}$.

U. S. Army. 1984. Shore Protection Manual. U. S. Government Printing Office. $1.088 \mathrm{hlm}$.

U. S. Army. 2008. Coastal Engineering Manual. U. S. Government Printing Office. Washington D.C. 